\title{
Students' experiences of inter-professional education through International Classification of Functioning-based activities at a community-based rehabilitation centre
}

\author{
M Kloppers, ${ }^{1}$ MOccTher; H E Koornhof, ${ }^{2}$ MNutr; J Bester, ${ }^{1}$ MPhil (Higher Education); F Bardien, ${ }^{3}$ MAud \\ ${ }^{1}$ Division of Occupational Therapy, Department of Interdisciplinary Health Sciences, Faculty of Medicine and Health Sciences, Stellenbosch University, Cape Town, South Africa \\ ${ }^{2}$ Division of Human Nutrition, Department of Interdisciplinary Health Sciences, Faculty of Medicine and Health Sciences, Stellenbosch University, Cape Town, South Africa \\ ${ }^{3}$ Division of Speech, Language and Hearing Therapy, Department of Interdisciplinary Health Sciences, Faculty of Medicine and Health Sciences, Stellenbosch University, Cape Town, South Africa
}

Corresponding author: M Kloppers (maatje@sun.ac.za)

Introduction. The training of healthcare professionals is faced with many challenges. To ultimately strengthen the health system, training has to respond to new health challenges, health science developments and societal needs. The Bishop Lavis Primary Health Care Project was established in 1993 and led to the establishment of the Bishop Lavis Rehabilitation Centre (BLRC). The current inter-professional service delivery at the Centre is based on the World Health Organization's International Classification of Functioning (ICF) model for holistic client-centred care. The objective of this article is to describe the students' experiences of inter-professional education (IPE) through ICF-based activities at BLRC.

Methods. Data were gathered from a retrospective review of student feedback forms from 2010 to 2012. Content analysis was employed to identify key themes regarding IPE.

Results. Inter-professional learning was found to occur spontaneously between the four allied health professions as a result of the ICF model-driven activities at BLRC.

Conclusion. Feedback at the end of the students' clinical placement was open ended and no information was asked specifically about IPE. More than half of the students spontaneously mentioned that learning about working in an inter-professional team as one of the highlights of their placement at BLRC, has prompted the sharing of this information. This article offers a potential framework (ICF) that fosters and supports the IPE philosophy in a clinical setting.

Afr J Health Professions Educ 2015;7(1):22-25. DOI:10.7196/AJHPE.289

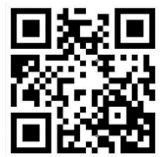

The education of health professionals needs to respond to new health challenges, health science developments and health needs of society to strengthen the health system. Frenk et al. ${ }^{[1]}$ reported the findings of the Lancet's Global Independent Commission into the Education of Health Professionals for the 21st century, and stated that the education of health professionals has not kept pace with the major challenges of providing health security to all. Some of the problems mentioned by the Commission include: poor teamwork; narrow technical focus without broader contextual understanding; mismatch of competencies with regard to patient and population needs; episodic encounters rather than continuous care; and predominant hospital orientation at the expense of primary care. The Commission believes that academic institutions are liable for these problems, as curricula are fragmented, outdated and static. ${ }^{[1]}$ The training of healthcare professionals is indeed a challenge and needs to ensure that entry-level professionals are equipped with the necessary skills and competencies to provide the highest standard of care for their clients. In South Africa (SA), the Health Professions Council of South Africa (HPCSA) promotes the health of all South Africans 'by determining standards of professional education and training and setting and maintaining the highest standards of professional and ethical behaviour for its registered healthcare professionals. ${ }^{[2]}$ This is achieved by establishing and monitoring the standards of professional education and training of the different healthcare professionals and setting standards for professional and ethical conduct of qualified professionals registered with the HPCSA. The different professional bodies each have guidelines that determine the content of the different courses, but the core ethical values and standards for good practice are generic and apply to all healthcare professionals. The core ethical values and standards for good practice are respect for persons, beneficence, non-maleficence, human rights, autonomy, integrity, truthfulness, confidentiality, compassion, tolerance and justice. ${ }^{[3]}$

Training for the healthcare professions has to include a comprehensive approach that addresses the needs of all South Africans, including skills to provide health promotion, health prevention, and curative and rehabilitation services. Healthcare professionals also need to be trained in social and technical skills to work together as a team. ${ }^{[4]}$ Since 1993, the healthcare system in SA has been expanded, transformed and revitalised, and parallel to this there have been major growth and developments in health science, professional education and training. ${ }^{[5]}$ Concurrently, an increased understanding of the value and need to include inter-professional education (IPE) in the training of healthcare students has developed. ${ }^{[1,6]}$ IPE is defined as: 'When two or more professions learn with, from and about each other to improve collaboration and the quality of care. ${ }^{\left[{ }^{[7]}\right.}$ IPE can be utilised to prepare healthcare students for effective inter-professional practice, as it enhances their knowledge and understanding of the skills, roles and responsibilities of other healthcare professions and builds an awareness of the value and importance of collaboration and teamwork. 
Effective inter-professional teamwork is one way to improve healthcare delivery and maximise healthcare outcome. ${ }^{[8]}$

The Bishop Lavis Primary Health Care Project ${ }^{[9]}$ was established in 1993 as a result of a partnership between the Faculty of Medicine and Health Sciences at Stellenbosch University (SU), Western Cape Government health authorities, City of Cape Town and Bishop Lavis community. The initial focus of this project was to assist with the reorientation of the healthcare services and deliver a comprehensive service. From the onset, an inter-professional approach was used involving nurses, family medicine practitioners, a physiotherapist, an occupational therapist, a social worker, a dietician and voluntary community workers. Establishment of community participation was an integral part of the project, where students and staff have worked together with community volunteers and the community health committee with regard to service, research and community development. The Bishop Lavis Rehabilitation Centre (BLRC) was established, which currently delivers an inter-professional service that includes physiotherapy (PT), occupational therapy (OT), speech-language and hearing therapy (SLT), and dietetic (DT) students and community volunteers. A number of successful, sustainable community-based intervention programmes and activities have been established through this partnership. These programmes are needs driven and initiated by BLRC's inter-professional team in collaboration with the community, and are now independently managed by community members with support from BLRC. Examples of these programmes are the weekly stroke support group and bi-weekly exercise and aerobics group. The latter was established because of a need identified by the BLRC team for physical activity and weight management to enhance the wellness of community members. In partnership with the community, members were trained and helped to establish the aerobics and exercise group, which is now independently managed by a community member.

The services rendered at BLRC are based on the World Health Organization (WHO)'s International Classification of Functioning (ICF) model ${ }^{[10]}$ for holistic patient-centred care. The ICF model places the focus of assessment on 'health' and 'functioning' rather than 'disability' and 'illness'. Based on the ICF model, the three domains of a client's functioning, i.e. activity, participation and body functioning and structures, are addressed while taking into account the environmental and personal factors also influencing the client's functioning. ${ }^{[10]}$ Research by Kloppers ${ }^{[1]}$ showed that a significant improvement in clients' functioning is achieved with this approach. Prevention and promotion activities performed by the BLRC inter-professional team address these contextual factors. The Western Cape Department of Health's plan for the re-engineering of primary healthcare ${ }^{[12]}$ is currently being developed and focuses on teamwork and reaching clients in their home environments. The core services delivered to the Bishop Lavis community by BLRC already encompass this vision. ${ }^{[1]}$

This article describes how this service allows students to be trained in an inter-professional manner to ensure optimal and holistic client and community rehabilitation. A description of the services rendered at BLRC explains the context in which the training takes place.

\section{Description of BLRC services}

In 1993, members of the Faculty of Medicine and Health Sciences, $\mathrm{SU}$, realised the need for a training platform within a community to give students an opportunity to become involved in and be exposed to primary healthcare and planning and delivery of healthcare services to
Table 1. Students trained annually at the Bishop Lavis Rehabilitation Centre

\begin{tabular}{lll}
\hline Profession & $\boldsymbol{n}$ & Study year \\
\hline Dietetics & 32 & Fourth (final) year \\
Occupational therapy & 12 & Fourth (final) year \\
Occupational therapy & 6 & Third year \\
Physiotherapy & 15 & Fourth (final) year \\
Physiotherapy & 18 & Third year \\
Speech-language and hearing therapy & 9 & Fourth (final) year
\end{tabular}

a community, based on the needs of that community. ${ }^{[9,13]}$ The services of BLRC are planned and managed by a full-time SU-appointed occupational therapist and physiotherapist with an inter-professional approach. Services and care facilities in the Centre are shared by all professions, which provides opportunities for informal inter-professional learning.

BLRC has developed services to address the health needs of the Bishop Lavis community and training needs of SU students. It started with only occupational therapy and physiotherapy services being delivered at the Centre and dietetic services at the community health centre, with sporadic contact for health promotion. Speech-language and hearing therapy services started intermittently from 1995, owing to the lack of a full-time speech therapist at the Centre. Since 2004, this service has been offered on a fulltime basis during student trimesters. From 2012, dietetic students formed an integral part of the services rendered at the Centre. Approximately 92 students are trained at BLRC annually, with average placement duration of 6 - 7 weeks per student. Table 1 gives a breakdown of the number of students per programme. The number of hours worked per student per week ranges from 20 to 40 .

The generic aims for students' involvement at BLRC are as follows: (i) developing an understanding of the role and responsibilities of the different members of the rehabilitation team; (ii) assisting in the rendering of a comprehensive therapy service to the Bishop Lavis community by developing an understanding of the humanity of clients and willingness to take holistic responsibility for clients - broader than the defined professional role of caring; (iii) enabling the development and adoption of ethical values and standards for good practice, i.e. respect for persons, beneficence, non-maleficence, human rights, autonomy, integrity, truthfulness, confidentiality, compassion, tolerance and justice, as prescribed by the HPCSA; (iv) providing the opportunity to gain training in community-based rehabilitation; and $(v)$ providing the opportunity for engaging in inter-professional communication and co-operation.

The service rendered at the Centre and in the community by the four disciplines and community volunteers is based on the ICF model, which ensures a holistic approach to client care and community interventions. This is achieved by assessing clients' and group members' activity and participation needs and taking into account the environmental and personal factors that could influence performance. Intervention services are planned in a weekly inter-professional team discussion. Disciplines then co-ordinate their input according to the client's needs to improve, adapt or maintain current functioning so that all involved can lead healthy and fulfilling lifestyles. 
The service, and how it lends itself to being inter-professional, is explained as follows:

- Management of clients on a one-on-one basis. Students are encouraged to 'shadow' other professionals, with the clients allocated to them for management. They conduct joint treatment sessions so that clients receive comprehensive treatment where applicable. If more than one profession is involved in the treatment, the client's name is added to the board in the student room and the names of the persons from the different professions involved in the client's management are added to four columns next to the client's name. This board facilitates communication between the different members of the inter-professional team. The goals for the client's rehabilitation are discussed weekly with an inter-professional team and is facilitated by the occupational therapist and physiotherapist. Referrals to appropriate services not delivered at BLRC are also discussed and done as required.

- Therapeutic and rehabilitative groups. Clients receive holistic input from inter-professionally designed group programmes to address all their rehabilitation needs. Students have the opportunity to either present part of the programme or shadow other professionals presenting it.

- Home/work visits. As part of a client's holistic rehabilitation, they are also treated in their home and work environment as needed. At least two different professionals should conduct the visit, which gives students the opportunity to experience the role/scope of other professions.

- Community outreaches. Training of home-based carers and volunteers, and health education talks, are planned and implemented interprofessionally. Students of at least two of the four professions are responsible for the planning and implementation of this service. The national health calendar and four seasons of health-promotion documents are used for planning the monthly themes covered in health education.

All administrative duties at BLRC are done in an inter-professional manner, e.g. documenting progress notes in one file per client, and co-ordinating the scheduling of clients' appointments in diaries, as this ensures time- and cost-effective services.

\section{Methods and analysis}

This qualitative study describes students' experiences of inter-professional learning. Data were obtained from anonymous student feedback forms. At the end of their clinical placement at BLRC, students were requested to fill in feedback forms as part of the quality assurance process to optimise learning opportunities.

The completion of student feedback forms is voluntary and anonymous and students were allowed to independently answer questions in a private area after completion of their final evaluation. The feedback forms contained open-ended questions about their learning experience at BLRC, e.g. highlights and barriers of the clinical placement. No specific questions about inter-professional learning were included.

Convenience sampling was employed and all students completing clinical placement at BLRC between 2010 and 2012 who handed in their forms were included in the study. A total sample of 124 out of a possible 209 students was obtained (DT: $n=32$; OT: $n=46$; PT: $n=36$; SLT: $n=10$ ). Ethical approval for using the data was obtained from the SU Health Ethics Research Committee (X13/12/018). The anonymity of the students was maintained throughout data collection and no identifying information was used on the feedback forms during analysis.
Credibility of the data collection process was ensured by employing triangulation of data sources, as the collection time spanned over 3 years and consisted of four different groups of health professions students. ${ }^{[14]}$

These qualitative data were analysed by employing an inductive approach, and three key themes relating to inter-professional work were identified. Credibility, transferability and dependability were applied during the data analysis process to ensure trustworthiness of the findings. Credibility was obtained by applying theoretical triangulation through reviewing of the most recent literature confirming or contradicting the themes that emerged from the data analysis. The coding of data was done by one of the researchers not involved in the supervision of the students, and peer review by the other three researchers by generating their own code lists, which were then compared with those of the first researcher. These codes were discussed and altered until consensus was reached. ${ }^{[14]}$

Transferability and dependability were obtained by giving a detailed description of the participants, research methodology and setting to determine applicability to a different setting and by using a sample of convenience. ${ }^{[14]}$

\section{Results}

More than half of the students spontaneously answered that 'working in an inter-professional team' was a highlight of their placement at BLRC. Students felt that they learned a great deal about the role of other professions in the management of their clients and about the role of their profession. The three themes that emerged are described below and are illustrated by direct quotes from the different professionals.

\section{Theme 1. Inter-professional teamwork}

Inter-professional teamwork encompasses the important aspects of clear communication between all, learning to work with one another and to respect the input of all towards addressing the needs of the client.

'Everyone gets an opportunity to give input on what would be best ... it felt like they did value our discipline in order to give the best to the patient'. [DT, 2012] 'I have learned a lot ... how important it is to communicate so that the different professions can complement each other'. [OT, 2012]

'To experience the way the multi-professional team should work together was a very good learning opportunity?' [PT, 2011]

'A good learning experience to be put in that situation and learn how to work with other professionals.' [SLT, 2012]

\section{Theme 2. Role identity of own profession}

This theme alludes to the important realisation by students of the scope of practice of their profession and affirmation of their career choice.

'During the meeting I realised that dietetics has a strong focus on treatment and prevention but also includes rehabilitation, whilst the physio, occupational and speech, language and hearing therapists' biggest focus was rehabilitation.' [DT, 2012]

'Working with all the different professions ... I feel much more confident ... that OT is what I want to do and why it is such a fulfilling occupation. [OT, 2012]

'... helped me to learn in different ways, helped me to grow and contributed to my positive experience ... ? [PT, 2011]

'Ultimately it made me a better therapist. It made me rethink my therapy goals and approach to therapy' [SLT, 2011] 


\section{Theme 3. Role of other professions}

The importance of learning from one another and to take cognizance of the role and inputs of other professions are highlighted in this theme.

'... was a nice learning experience where I got to see what other roleplayers of the inter-disciplinary team do.' [DT, 2012]

'Working with all the different professions' students and seeing where everyone fits into the team.' [OT, 2012]

'I enjoyed working with the multi-professional team and I was able to learn more about OTs and SLTs and when referrals might be appropriate in the future.' [PT, 2011]

'Listening to other professionals and understanding what their role is. [SLT, 2012]

The activities mentioned by students within these themes, which they noted as contributing to their learning opportunity while doing practical training at BLRC, were weekly inter-professional team discussions, group therapy sessions, home visits and team socials.

\section{Discussion}

At BLRC, the WHO ICF model is used because of its inclusive focus on health, well-being and functioning, ensuring optimal care for individuals and the community. The ICF is therefore also acknowledged internationally as being suitable for educational and training purposes. Although the different disciplines involved at BLRC have their specific scope of practice, the ICF model allows them to work collaboratively to achieve and provide holistic care for their clients. The use of the ICF model guided and aligned assessment and management of clients by students from different professions, and then assisted in the collaborative planning of the diverse profession-specific, yet suitable, interventions.

The Lancet's Global Independent Commission into the Education of Health Professionals for the 21st century suggests that inter-professional education is one of the methods that will ensure effective teamwork. ${ }^{[1]}$ The three themes identified in this study describe professional attributes that are important outcomes of inter-professional practice as well as essential qualities to achieve optimal and holistic client care that is realised when using the ICF model. Through their inter-professional teamwork, the students reported that they had not only developed a strong understanding of their own unique role and expertise, but also respect for each other's roles and contribution towards client care. The themes identified are not unique, as Nisbet et al. ${ }^{[6]}$ also reported the vital role of IPE to assist students in developing effective interprofessional communication and teamwork competencies.
Further research is necessary to investigate the full potential of ICF as a framework to support the IPE philosophy in a clinical setting.

\section{Conclusion}

It seems as though the manner in which the Centre is managed, with weekly inter-professional team discussions, team socials, joint home visits and treatment sessions, with the ICF model guiding client-directed activities, spontaneously lends itself to IPE between students from different professions. ICF-based activities not only ensured a holistic approach to client care, but also facilitated students learning from other professions and about their own profession.

No specific information was requested regarding IPE in the feedback forms provided to the students. More than half of the students spontaneously mentioned learning about working in an inter-professional team as one of the highlights while at BLRC, which prompted us to share this information. The value of this article is that it offers a potential framework (ICF) that fosters and supports the IPE philosophy in a clinical setting. Further investigation into the range and depth of this learning experience has been initiated.

\section{References}

1. Frenk J, Chen L, Bhutta ZA, et al. Health professionals for a new century: Transforming education to strengthen health systems in an interdependent world. Lancet 2010;376(9756):1923-1958. [http://dx.doi.org/10.1016/S01406736(10)61854-5]

2. Dhai A, Mkhize B. The Health Professions Council of South Africa and the medical practitioner Continuing Medical Education 2006;24(1):8.

3. Health Professions Council of South Africa. Guidelines for Good Practice in the Health Care Professions - General Ethical Guidelines for the Health Care Professions. Booklet 1. The Human Rights, Ethics and - General Ethical Guidelines for the Healt 0

4. Declaration of Alma-Ata. International conference on primary health care, Alma-Ata, USSR, 1978. http://www. who.int/publications/almaata_declaration_en.pdf (accessed 23 January 2015).

5. Schaay N, Sanders D. International perspective on primary health care over the past 30 years. In: Barron P, RomaReardon J, eds. South African Health Review 2008. Durban: Health Systems Trust, 2008:3-16.

6. Nisbet G, Hendry GD, Rolls G, Field MJ. Interprofessional learning for pre-qualification health care students: An outcomes-based evaluation. J Interprof Care 2008;22(1):57-68. [http://dx.dol org/10.1080/13561820701722386]

7. CAIPE. Interprofessional education - a definition. 2002. http://www.caipe.org.uk/resources/ (accessed 27 September 2012). 8. Lê Q, Spencer J, Whelan J. Development of a tool to evaluate health science students' experiences of an interprofessional education (IPE) programme. Ann Acad Med Singapore 2008;37(12):1027.

9. De Villiers MR, Asia MB, Dreyer MY, Koornhof MHE, Statham MS. Training the primary health care team. SA Fam Pract 1996;17(3):111-117

10. World Health Organization (WHO). Towards a Common Language for Functioning, Disability and Health ICF. Geneva: WHO, 2002. http://www.who.int/classifications/icf/training/icfbeginnersguide.pdf (accessed 27 September 2012).

11. Kloppers M. Die uitkomste wat fisies-gestremde kliënte bereik deur hul deelname aan rehabilitasie by 'n gemeenskapsrehabilitasiesentrum in die Wes-Kaap. Stellenbosch: Stellenbosch University, 2012 (unpublished dissertation).

12. Western Cape Department of Health. Re-engineering of primary health care for South Africa. 2012. http://www. uwc.ac.za/usrfiles/users/280639/CHW_symposium-NationalPHC_Reengineering.pdf (accessed 27 Septembe 2012)

13. De Villiers MR, Dreyer Y, Howes F, et al. Assessing the health needs of a community through participatory research. SA Fam Pract 1999;21(1):8-12.

14. Krefting L. Rigor in qualitative research: The assessment of trustworthiness. Am J Occup Ther 1991;45(3):214222. [http://dx.doi.org/10.5014/ajot.45.3.214] 